\title{
HANAC syndrome
}

INSERM

\section{Source}

INSERM. (1999). Orphanet: an online rare disease and orphan drug data base. HANAC syndrome. ORPHA:73229

A rare multisystemic disease characterized by small-vessel brain disease, cerebral aneurysm, and extracerebral findings involving the kidney, muscle, and small vessels of the eye. 